\title{
Edebiyat Çevirisinde Çevirmen ve Editör Kararları
}

\section{Esra BİRKAN BAYDAN 1}

\begin{abstract}
Öz
$\mathrm{Bu}$ makalenin amacı çevirmenlerin ve editörlerin edebiyat çevirisine yaklaşımlarını örnekler üzerinden göstererek aralarındaki farklılıkları tespit etmektir. Çeviri edebiyat eserleri çevirmenin yorumundan geçerek okura ulaşır. Edebiyat metinlerinde anlam akışkan ve çok katmanlı olduğu için edebiyat metinlerini çevirmek yoğun bir anlamlandırma ve yorumlama süreci içerir. Çevirmen bu süreçte, birden fazla çözümü bulunabilen çeviri sorunlarına yoğunlaşır, yaratıcllı̆ını kullanarak çözüm üretir ve olası çözüm seçenekleri arasından bilinçli tercihler yapar. Bilinçli tercihler yapmak anlamın sorumluluğunu almakla ilgilidir ve çevirmen, kararlarını metinden ve bağlamdan dayanak bularak gerekçelendirebilmelidir. Birinci bölümde, çeviri sorunları ve çevirmen kararlarına örnekler sunulacaktır. İkinci bölümde, editörlerin çevirmen kararları ile ilgili düşüncelerine yer verilecek ve editör düzeltilerinden örnekler sunulacaktır. Editör düzeltilerinde editörlerin, çevirmen tercihlerinin sebebini sorgulamadan genellikle tek tip çözümlere başvurdukları gözlemlenmiştir. Çevirmenlerin editörlerle işbirliği halinde çalışarak kendi kararlarını gerekçelendirmelerinin bu durumun aşılmasına katkı sağlayacağı sonucuna varılmıştır.
\end{abstract}

Anahtar kelimeler: Edebiyat çevirisi, çevirmenler, editörler, çeviri sorunları, anıştırma, metinlerarasılık, çeviri kararları.

\section{Translator and Editor Decisions in Literary Translation}

\begin{abstract}
This paper intends to demonstrate translators' and editors' approach to literary translation through examples and determine differences of opinion between them. Translated literary works reach their readers through the interpretation of translators. Since meaning is plural and in flux in literary works, translating them inevitably involves interpretation which is a necessary part of understanding the text. The translator focuses on translation problems which have more than one viable solution, uses his/her creativity to find solutions and makes conscious choices among various alternatives. Making conscious decisions is about taking the responsibility of meaning. The translator should be able to justify his/her choices in accordance with the text and context. Examples of translation problems and translator decisions will be presented in the first part of this paper. Editors' opinions about translator decisions and examples from their revisions will be provided in the second part. It was observed that editors generally tend to apply standard solutions in their revisions without giving much consideration to the reasons behind translators' choices. The paper concludes that translators could work in cooperation with editors to justify their choices as a way of overcoming any hindrances.
\end{abstract}

Key words: Literary translation, translators, editors, translation problems, allusions, intertextuality, decision making in translation.

Doç. Dr., Marmara Üniversitesi, Fen Edebiyat Fakültesi, Mütercim Tercümanlık Bölümü, esra.birkan@marmara.edu.tr [Makale kayıt tarihi: 19.6.2018-kabul tarihi: 15.8.2018] 


\section{Giriş}

Edebiyat metnini yorumlama ve anlamlandırma sürecinde çevirmen “çeviri sorunlarını"2 saptar ve yaratıcılığını kullanarak çeviri sorunlarına çözüm seçenekleri üretir. Dolayısıyla çeviri yapmak aynı zamanda olası seçenekler arasından tercihler yapmaktır ve karar vermeyi gerektirir. Kathleen Davis, Deconstruction and Translation (Yapısöküm ve Çeviri) adlı kitabında, çeviri yapmanın yazarın kastettiği anlamı korumak olduğu varsayımının yapısöküme uğradığını belirtir. Davis bunu şöyle açıklar: Anlam metnin ve belli bir bağlamın içinde varlık kazanır; bununla birlikte "metnin içindeki izlerin (traces) oyunuyla da kendinden farklılaşır veya ötelenir” (Davis, 2001, s. 53). Bir başka deyişle, söylenmiş (veya yazılmış) sözler, söylenmemiş sözlerin de izlerini taşır. Bir sözü anlamlandırırken, söylenmemiş sözleri de dikkate alarak, neden onların değil de bu sözün söylendiğini değerlendirir veya sözün neden başka bir şekilde değil de, bu şekilde ifade edildiğini dikkate alırız. Dolayısıyla yazarın kastettiği anlam, kapalı bir devre içinde gerçekleşmez; söylenmeyen sözlerin izleriyle ve bağlamın sınırsızlı̆̆ içinde çoğullaşır. Anlam doğrudan ulaşılabilir olmadığına göre, çıkarım yapmamız gerekir. Çeviri de böyle bir anlam çıkarma eylemi olduğuna göre, çeviride bazı anlamlar seçilirken, diğerleri dışarıda bırakılacak veya artakalacaktır; ama artakalan anlamların doğru olmadığı söylenemez. Metinde bulunması gereken tek bir doğru anlam olmadığına göre Davis, "metinden çıkarılan anlamın sorumluluğunun tamamıla çevirmene ait olduğu" sonucuna varır (s. 65). Çeviride karar vermenin "belirli seçenekler arasından doğru seçimi yapmak" anlamına gelmediğinin, bu nedenle de karar vermenin "sorumluluk almayı" gerektirdiğinin altını çizer (Davis, 2001, s. 51). Sonuç olarak, edebiyat metninin kesin bir anlamının olmaması, bir belirsizlik oluşturur. Bu da önceden doğruluğu tespit edilmiş bir seçeneğin olmadığı anlamına gelir. Dolayısıyla, çeviride karar vermek, önceden doğruluğu tespit edilmiş bir seçeneğe yönelmek değildir; yani bir sözcüğün veya ifadenin veya metnin tamamının dilde önceden belirlenmiş karşılığını bulmak değildir, çünkü böyle bir 'doğru' seçenek yoktur. Bu belirsizlik çevirmeni farklı düzeylerde kararlar vermeye yönlendirir ve çeviri eser çevirmen kararları ile biçimlenir.

Edebiyat çevirisinde çevirmenin karar vermesini gerektirecek pek çok çeviri sorunundan söz edilebilir. 3 Yazarın biçemi, kültürel öğeler, anıştırmalar, eğretilemeler, betimlemeler, sözcük oyunları, sosyolekt (topluluk dili4)/ idiolekt (bireysel dil5), sözcüklerin ses işlevi ve yoruma açlk, örtük ifadeler bunlardan yalnızca birkaçıdır. Bu yazının ilk bölümünde, "anıştırma” örnekleri üzerinden çevirmen kararları değerlendirilecek, ikinci bölümünde de çeviri eserin ortaya çlkmasında rol oynayan editörlerin çevirmen kararlarına yaklaşımları ve çevirmen kararları ile biçimlenen çeviri esere ne tür müdahalelerde bulundukları örneklendirilecektir.

\section{Bir Çeviri Sorunu Olarak Anıştırma}

Anıştırma, metinlerarasılık kavramıyla ilgili bir çeviri sorunudur. Graham Allen’a göre, metinlerarası kuramcılar iki kampa ayrılmıștır. Yapısalcı olan birinci kamp, incelenen metinle diğer metinler arasında metinlerarası bir ilişki olsa bile metnin anlamının belirlenebileceğini düşünür. Metni oluşturan unsurların ve bunların diğer metinlerle olan ilişkisinin tamamen çözümlenip anlamlandırılarak anlamı teke indirmenin mümkün olduğunu düşünür. Yapısalcllık-sonrası ise, metindeki anlamların diğer metinlerde izi sürülebilse bile anlamın belirlenip teke indirilemeyeceği görüşündedir (karş. Allen, 2000). Dolayısıyla anıştırma sorunu yapısalcı düşüncede çıkarıma kapalıyken, yapısalcılık-sonrasında

Nord’un tanımına göre, “çeviri sorunu” birden fazla çözümü olan ve çevirmenin yeterliliğinden bağımsız olarak, her çevirmenin üzerine kafa yorması gereken bir durum ortaya koyar. (Nord, 2005, s. 166-167)

Bkz. Birkan Baydan, 2016, s. 49-88

Bkz. Berk, 2005, s. 194

Bkz. Berk, 2005, s. 191 
öznel çıkarıma ve farklı çözümlere açıktır ve yorumlarla çoğullaşır. Bu iki yaklaşımla ilgili iki ayrı kavramdan söz edebiliriz: "metinlerarasılık" ve "metinsel aşkınlık"

"Metinlerarasılık" yapısalcılık-sonrası yaklaşıma göre Kristeva tarafından ortaya konmuş bir kavramken, "metinsel aşkınlık" Genette'in kendi yaklaşımını yapısalcılık-sonrası yaklaşımlardan ayırdetmek için kullandığı bir kavramdır. Kristeva "edebi sözün, bir nokta (yani sabit bir anlam) olmadığını, metinlerarası diyalogda metinlerin kesişme noktasını oluşturduğunu” belirtir (Kristeva, 1986, s. 36). Genette (1997) ise "metinsel aşkınlık" kavramını metinlerin sistematik olarak nasıl yorumlanıp anlaşılacağını göstermek için kullanır. Genette'de metinlerarasılık, metinsel aşkınlığın altındaki beş kategoriden biridir. "Anıştırma" (allusion) ise metinlerarasıllı̆ın altındaki üç kategoriden biri olup diğerleri "alıntı" (quotation) ve "çalıntı"dır (plagiarism). Cuddon ise anıştırmayı, "edebiyat metnine çağrışım yoluyla zenginlik veya derinlik kazandırmak için başka eserlere yapılan genellikle örtük göndermeler" şeklinde tanımlar (Cuddon, 1985, s. 31). Çevirmenin anıştırmayı fark etmesi, sonra da kendi kültürü bağlamında bir değerlendirme yaparak nasıl çevireceğine karar vermesi gerekir. Dipnotla açılamak, anıştırmayı olduğu gibi bırakmak, açımlayarak vermek, (tarihsel ya da kültürel uzaklık nedeniyle) anıştırmayı çıkarmak veya başka bir anıştırma bulmak olası çözümler arasındadır.

Lefevere anıştırmayı dört grupta inceler: Kutsal kitap anıştırmaları, klasik anıştırmalar, kültürel anıştırmalar, edebî anıştırmalar. Kutsal kitap anıştırmaları İncil'e yapılan göndermeleri; klasik anıştırmalar tarihi kişiler, yerler, tarihi olaylar ve mitolojilere yapılan göndermeleri; kültürel anıştırmalar belli bir kültüre özgü olaylar, kişiler ve yerlere yapılan göndermeleri; edebî anıştırmalar ise başka edebiyat eserlerine yapılan göndermeleri içerir (Lefevere, 1992, s. 22-29). Aşağıda mitolojik ve edebî anıştırma örneklerí6 incelenecektir.

Birinci örnek, Patricia Highsmith’in Talented Mr. Ripley (Yetenekli Bay Ripley) adlı eserinin iki farklı çevirisinden bir mitolojik anıştırma örneği; ikincisi ise aynı eserden edebî anıştırma örneğidir. Her iki örnekte de çevirmenlerin bir çeviri sorunu olan anıştırma ile ilgili olarak verdikleri kararlar ve uyguladıkları farklı stratejiler görülmektedir.

\section{ÖRNEK 1:}

KM: He was afraid of nameless, formless things that haunted his brain like the Furies. (Highsmith, 1999, S. 186)

EM1:7 Adı ve biçimi belirsiz, soyut bir 'Kötü Güç’tü onun kafasındaki korkuyu yaratan. (2001, s. 211)

EM2: ${ }^{8}$ Tom, Erinyeler gibi ismi ve biçimi olmayan şeylerin yakasına yapışmasından korkuyordu. (2016, s. 234)

(Ç.N. Yunan ve Roma mit. öç alma tanrıçaları.)

Furies, Türkçede Erinyeler 9 olarak bilinen mitolojik karakterlerdir. Anlatıma çağrışım yoluyla derinlik kazandıran anıştırmalara örnek olarak gösterilebilir. Romanın kahramanı Tom Ripley bir cinayet işlemiş, fakat bu cinayetten yargılanmaktan kurtulmuştur. Bu konuda vicdanı rahatmış gibi görünür. Ancak Erinyeler'den korkması vicdanının rahat olmadığını, huzursuz olduğunu gösterir. Çünkü mitolojide Erinyeler suçluları bulup cezalandıran, onlara işkence eden varlıklardır. Tom Ripley’in suçunun cezasız kalmadığını, ruhunun çektiği işkence ile suçunun bedelini her gün ödediğini anıştırma

Bu örnekler ve diğer anıştırma örnekleri için Bkz. Birkan Baydan, 2016.

2001'de yayımlanan Armağan İlkin çevirisi.

2016'da yayımlanan Esra Birkan çevirisi.

Bkz. Azra Erhat Mitoloji Sözlüğü. 
yoluyla anlatmaya hizmet eder. Birinci çevirmen Furies’i açımlama yoluna gitmiş, ikinci çevirmen ise dipnotla açıklamıştır.

ÖRNEK 2:

KM: Ten thousand saw I at a glance, nodding their heads in sprightly dance,' Dickie said sourly to Tom. (Highsmith, 1999, s. 86)

EM1: Dickie, "Binini gördüm o anda, dans ederken alanda," diyerek ikisinin de bildiği bir şiirin iki dizesini okudu askk yüzle. (2001: 101)

EM2: "On bin tane gördüm bir bakışta, kafalarını sallıyorlardı coşkulu bir dansta," dedi Dickie buruk bir tonda. (2016: 110)

(Ç.N. William Wordsworth’ün “Daffodils” (Nergisler) şiirinden bir dize.)

William Wordsworth'ün, "I Wandered Lonely as a Cloud" (Yalnız bir bulut gibi dolaştım) olarak da bilinen, bir bulutun üstündeyken hissedilen doğayla bütünleşme hissini, ütopik bir yerde hissedilen neşe ve huzurun gerçeklikten farklı olduğunu anlatan "Daffodils" (Nergisler) adlı şiirinden yapılan bu alıntıyı her iki çevirmen de fark etmiştir. Birinci çevirmen, "ikisinin de bildiği bir şiirin iki dizesini okudu" eklemesini yaparak açımlama yoluna gitmiş, ikinci çevirmen ise, bu dizenin hangi şiirden olduğunu dipnotla açıklamıştır. Tom'dan giderek soğuyan ve onunla istemediği bir seyahate çıkan Dickie'nin neşeyi anlatan bir dizeyi asık bir yüzle (EM1) veya buruk bir tonda (EM2) söylemesinin, onun da şair gibi artık buluttan indiğini ve Tom'un gerçek yüzünü görmeye başladığını anıştırma yoluyla anlatmaya hizmet ettiği düşünülebilir.

Anıştırma örneklerinde de görüldüğü üzere, başka metinlerle diyaloğa giren etkileşim kuran edebiyat eserlerinde anlam çoğullaşmakta ve çok katmanlı ve çok sesli olmaktadır. Çevirmenin yöneleceği tek bir doğru çözüm olmadığından edebiyat çevirisinde anlam çevirmen kararlarıyla şekillenir ve yukarıda da bahsettiğimiz gibi, anlamın sorumluluğu çevirmendedir. Aşağıda, edebiyat çevirisinin diğer aktörleri olan editörlerin çevirmen kararlarına ne ölçüde müdahale ettikleri incelenecektir.

\section{Editör Kararları}

Türkiye'de yayınevlerinin büyük bir çoğunluğunda yeterince kurumsallaşmış bir yapı bulunmadığından, editörlerin görevleri de çok net bir biçimde ayrışmamıştır. Editörlerin görevlerinden biri de çevirmenden gelen çeviriyi kaynak metinle karşılaştırarak okumak ve gerekli düzeltileri yapmaktır. Redaktörler ise Türkçe metindeki anlatım bozukluklarını ve yazım hatalarını düzeltir.

Editörlerin çeviri metne ne ölçüde müdahale ettiğini anlatan sözlerini değerlendirdiğimizde; "çevirmen tercihlerine karışmadıklarını" (Birkan, 2012, s. 71-72; Akaş, 2011, s. 24), dil (çeviri) sorunlarını "editörden daha fazla ciddiye alan ve çözümler üreten çevirmenler"in tercihlerine saygı duyulması, çevirmenin ürününün de "bir eser" olarak kabul edilmesi gerektiğini (Bora, 2005, s. 11), "metin üzerinde çalışırken her zaman çevirmenin mantığını çözmeye, o bölümü niye öyle çevirdiğini anlamaya çalıştığını” (Sabuncuoğlu, 2016, s. 288) belirten editörler olduğunu görüyoruz.

Editörlerin yaptıkları düzeltileri değerlendirdiğimizde ise genellikle sözcük seçimi, sözdizimi, deyimler, kalıplaşmış ifadeler, kültürel öğeler ve anıştırma boyutunda düzeltme yaptıkları söylenebilir. Sözcük seçimi boyutunda, yabancı dillerden dilimize giren sözcükler ve eski sözcükler ile ilgili düzeltiler yapıyor ve genellikle bunları Türkçe karşılıklarıyla değiştiriyorlar. Sözcük seçimi boyutunda, çevirmenlerin biçemsel kaygılarla, örneğin atmosfer yaratma amacıyla, tarihselleştirme stratejisi uygulayarak eski sözcüğü tercih etmesi veya karakter yaratma amacıyla yabancı dildeki sözcüğü tercih etmesinin bu genel 
uygulama çerçevesinde editörler tarafından çok fazla dikkate alınmadığı görülmektedir. Sözdizimi boyutunda editörlerin genellikle olumlu katkıları olduğunu söyleyebiliriz.

Deyimler, kalıplaşmış ifadeler konusunda, "Hay Allah”, "tek bir Allahın kulu” gibi kalıplaşmış ifadeler günlük hayatta herhangi bir ideolojik çağrışım taşımadıı̆ı halde, editörler bu ifadeleri "hey Tanrım” ya da "lanet olsun sana" gibi daha yapay ifadelerle değiştirebilmektedir. Böyle durumlarda çevirinin Türkçeye değil, çeviriler için kullanılan bir Türkçeye, yani bir "çeviri diline” çevrildiğinden söz edilebilir. Kültürel öğeler konusunda editörler genellikle yabancılaştırma stratejisini tercih etmektedir. Editörler tarafından yabancılaştırma stratejisinin genel bir uygulama olarak kabul edilmesi kimi zaman metnin bağlamını gözden kaçırmalarına sebep olabilmektedir. Örneğin, Nazi kampından kurtulan Polonyalı bir kadının Amerika'daki hayatını anlatan bir eserde, Amerika'daki göçmenler kendi kültürlerine özgü yemeklerden bahsettikleri için, çevirmenin "lokma" sözcüğünü tercih etmesi metnin bağlamın gözeterek aldığı bir karardır. Editörün "şekerli çörek" şeklinde bir düzelti yapması çevirmenin neden o sözcüğü tercih ettiğini anlamadığını gösterir. Anıştırma örneklerinde anıştırma sorununun tek bir çözümü olamayacağından bahsetmiştik. Ne var ki, editörler anıştırmanın örtük olup olmadığına dikkat etmeksizin, genellikle dipnot koyarak açıklamayı tercih etmektedir.

\section{Sonuç}

Edebiyat çevirisi birtakım kurallara göre yapılabilecek bir etkinlik değildir. Her edebiyat eseri çevirmeni farklı çeviri sorunlarıyla karşı karşıya bırakır ve çevirmen metni anlamlandırma ve yorumlama sürecinde sorunları saptayarak çevirisinde bunları çözmeye çalışır. Çeviri eser çevirmenin sözcük seçiminden kültürel unsurlara kadar her düzeyde verdiği kararlarla şekillenir. Okura ulaşan çeviri eserin ortaya çıkmasında çevirmenler kadar editörlerin de payı vardır. Editörlerin çevirmen tercihlerine saygı duyduklarını belirtmelerine rağmen kimi zaman çevirmenin karakter yaratma, atmosfer oluşturma ve benzeri biçemsel kaygılarla veya metnin bağlamını gözeterek benimsediği çeviri stratejilerini fark etmedikleri gözlenmiştir. Bu durumun, çevirmenlerin bilinçli tercihlerinin sebebini anlama gayreti içine girmemelerinden kaynaklandığı düşünülmektedir. Öyleyse, çevirmenlere düssen görev, kendi tercihlerini metne ve bağlama dayandırdıkları gerekçelerle açıklayabilmektir.

Çevirmenler zaman içinde çeviri sorunları ile ilgili çeşitli stratejiler geliştirir. Çeviri kuramlarını bilen bir çevirmenin çeviri stratejileri konusunda daha geniş bir perspektife sahip olacağını ve çeviri sorunlarının çözümü konusunda farklı ve çeşitli stratejilere başvurabileceğini söylemek yanlış olmaz. Ancak gözlemlendiği kadarıyla editörlerin, eski sözcükleri yenileriyle değiştirmek, her durumda dipnot kullanmak, kültürel öğelerle ilgili her durumda yabancılaştırma stratejisi kullanmak gibi genellikle tek tip çözümlere başvurdukları görülmektedir. Sonuç olarak, editörlerin belli bir ezbere göre hareket ettikleri, standartlaşmış, kalıplaşmış, hatta çalıştıkları yayınevlerinde "norm" haline gelmiş bir "çeviri diline" göre düzelti yaptıkları söylenebilir. Çevirmenlerin çevirdikleri eseri yayınevine teslim ettikten sonra editörün düzeltilerini incelemesi ve kendi tercihlerini açıklayarak editörle işbirliği halinde çalışmasının bu durumun aşılmasına katkıda bulunacağı düşünülmektedir.

\section{Kaynakça}

Akaş, C. (2011). “Editörlük: Tanı, Seyir, Tedavi”. Notos. Sayı 27: 23-28.

Allen, G. (2000). Intertextuality. London: Routledge.

Berk, Ö. (2005). Kuramlar Işığında Açıklamah Çeviribilim Terimcesi. İstanbul: Multilingual.

Birkan, Tuncay. (2012). "Editörlere Sorduk”. Ç.N. Çeviri Edebiyatı 16: 70-74. 
Birkan Baydan, E. (2016). Edebiyat Çevirisinde Sahneler ve Aktörler. İstanbul: Diye.

Bora, Tanıl. (2005). “Editör Kimdir, Eserleri Nelerdir?” Kül Eleştiri. Sayı 2, Nisan-Mayıs: 4-12.

Cuddon, J.A. (1985). A Dictionary of Literary Terms. London: Penguin.

Davis, K. (2001). Deconstruction and Translation. Manchester: St. Jerome.

Erhat, A. (1989). Mitoloji Sözlüğ̈̈. İstanbul: Remzi Kitabevi.

Genette, G. (1997). Palimpsests: Literature in the Second Degree. Nebraska: University of Nebraska Press.

Highsmith, P. (1999). The Talented Mr. Ripley. London: Vintage.

Kristeva, J. (1986). "Word, Dialogue and Novel". In Toril Moi (Ed.), The Kristeva Reader (s. 35-61). Oxford: Blackwell.

Levefere, A. (1992). Translating Literature: Practice \& Theory in a Comparative Literature Context. New York: The Modern Language Association of America.

Nord, C. (2005). Text Analysis in Translation: Theory, Methodology, and Didactic Application of a Model for Translation-Oriented Text Analysis. (çev. Christiane Nord \& Penelope Sparrow). Second Edition. Amsterdam \& New York: Rodopi. 